\title{
Análise-físico química do álcool adquirido em estabelecimentos comerciais do município de Vitória da Conquista-Bahia
}

\author{
Physical and chemical analysis of alcohol purchased in commercial establishments in the \\ municipality of Vitória da Conquista-Bahia \\ Análisis físico-químico de alcohol adquirido em establecimientos comerciales del município de \\ Vitória da Conquista-Bahía
}

\section{Resumo}

O consumo de álcoois a $70 \%$ aumentou significativamente em todo o mundo após a pandemia do novo coronavírus (Covid-19). Em razão do surgimento e do avanço desta doença e de suas variantes, tornou-se necessário que em todos os estabelecimentos públicos e privados, como pontos comerciais, estabelecimentos de serviços de saúde, lojas e de tráfegos, sejam adquiridos o álcool a 70\% utilizado como antisséptico e que se mostra bastante eficiente no combate de diversos parasitas, fungos, vírus e bactérias, já que esse produto foi projetado para eliminar 99,9\% desses germes. O objetivo desta pesquisa foi identificar o teor alcoólico e as características físico-químicas do álcool comercializado no centro de Vitória da Conquista. Trata-se de uma pesquisa experimental, contendo 1 amostra de $500 \mathrm{~mL}$ de 10 estabelecimentos distintos escolhidos aleatoriamente situadas no bairro Centro, as amostras compradas serão analisadas no laboratório da Faculdade Independente do Nordeste- FAINOR. A metodologia utilizada foi a realização de testes em 10 amostras de álcoois compradas nos estabelecimentos de Vitória da Conquista - BA, onde realizou-se ensaios organolépticos de aspecto, cor e odor, e físico químicos de $\mathrm{pH}$, viscosidade e teor alcoólico, visando se estas amostras estavam dentro dos padrões estabelecimentos pela ANVSA. Contudo Os resultados encontrados nesse estudo possibilitam concluir que 79 a $80 \%$ das amostras analisadas possuem teor alcoólico adequado segundo normas da ANVISA, e dessa forma possivelmente possuem eficácia contra o vírus SARS-CoV-2, já que para isso o álcool deve estar a 70\%. É importante ressaltar que preparações alcoólicas devem ser manipuladas por técnicos habilitados, com a documentação legal necessária para realizar a fabricação.

Palavras-chave: Álcool a 70\%; Controle de qualidade; Análises físico-químicas; Coronavírus.

\begin{abstract}
The consumption of $70 \%$ alcohols increased significantly worldwide after the pandemic of the new coronavirus (Covid19). Due Consumption of $70 \%$ alcohols increased significantly worldwide after the pandemic of the new coronavirus (Covid-19). Due to the emergence and advance of this disease and its variants, it has become necessary that in all public and private establishments, such as commercial points, health service establishments, shops and traffic, $70 \%$ alcohol used as antiseptic is acquired and which proves to be very efficient in the fight of various parasites, fungi, viruses and bacteria, as this product was designed to eliminate $99.9 \%$ of these germs. The objective of this research was to identify the alcohol content and the physical-chemical characteristics of the alcohol commercialized in the center of Vitória da Conquista. This is an experimental research, containing 1 sample of 500mL of 10 different establishments randomly chosen located in the Centro neighborhood, the samples purchased will be analyzed in the laboratory of the Independent College of the Northeast - FAINOR. The methodology ut ...to the emergence and progress of this disease and its variants, it became necessary that in all public and private establishments, such as commercial points, health services establishments, stores and traffic, 70\% alcohol used to be purchased as an antiseptic and shown to be quite efficient in combating several parasites, fungi, viruses and bacteria, since this product was designed to eliminate $99.9 \%$ of these germs. The objective of this project is to identify the alcohol content and the physical and chemical characteristics of
\end{abstract}


the alcohol sold in the center of Vitória da Conquista. A methodology with experimental research will be used, containing $1500 \mathrm{~mL}$ sample from 10 different establishments chosen randomly located in the Centro neighborhood, the purchased samples will be analyzed in the laboratory of Faculdade Independente do Nordeste - FAINOR.

Keywords: 70\% alcohol; Quality control; Physicochemical analysis; Coronavirus.

\section{Resumen}

El consumo de alcohol en un $70 \%$ aumentó significativamente en todo el mundo después de la nueva pandemia de coronavirus (Covid-19). Debido al surgimiento y avance de esta enfermedad y sus variantes, se ha hecho necesario que en todos los establecimientos públicos y privados, como puntos comerciales, establecimientos de servicios de salud, tiendas y tráfico, se compre alcohol al $70 \%$ usado. Como antiséptico y que demuestra ser bastante eficaz en el combate de diversos parásitos, hongos, virus y bacterias, ya que este producto fue diseñado para eliminar el 99,9\% de estos gérmenes. El objetivo de esta investigación fue identificar el contenido alcohólico y las características fisicoquímicas del alcohol comercializado en el centro de Vitória da Conquista. Se trata de una investigación experimental, que contiene 1 muestra de $500 \mathrm{~mL}$ de 10 establecimientos diferentes elegidos aleatoriamente ubicados en el distrito Centro, las muestras compradas serán analizadas en el laboratorio de la Faculdade Independente do Nordeste - FAINOR. La metodología utilizada fue la realización de pruebas sobre 10 muestras de alcoholes adquiridos en los establecimientos de Vitória da Conquista-BA, donde se realizaron pruebas organolépticas de apariencia, color y olor, y pruebas físicoquímicas de $\mathrm{pH}$, viscosidad y contenido alcohólico, en Para obtener estas muestras se cumplieron los estándares establecidos por ANVSA. Sin embargo, los resultados encontrados en este estudio permiten concluir que del 79 al $80 \%$ de las muestras analizadas tienen un contenido de alcohol adecuado según las normas ANVISA, y por lo tanto posiblemente tengan eficacia frente al virus SARS-CoV-2, ya que para ello el alcohol debe estar al 70\%. Es importante destacar que las preparaciones alcohólicas deben ser manipuladas por técnicos cualificados, con la documentación legal necesaria para llevar a cabo la fabricación.

Palabras clave: $70 \%$ de alcohol; Control de calidad; Análisis fisicoquímico; Coronavirus.

\section{Introdução}

Os primeiros casos do vírus SARS-CoV-2 foram notificados em dezembro de 2019 na cidade de Wuhan, na China. A doença espalhou-se rapidamente tornando-se um problema de saúde pública mundial e no dia 11 de março de 2020 a Organização Mundial de Saúde (OMS) a caracterizou como uma pandemia. A doença é transmitida pela via respiratória dos seres humanos que estiverem em contato próximo ou por secreções produzidas durante os episódios de tosse, espirros e coriza. Essas gotículas emitidas podem também contaminar objetos e o vírus pode permanecer nessas superfícies por horas ou dias (Oliveira, et al., 2020; Quintela et al.,2020).

Em razão do surgimento e do avanço desta doença e de suas variantes, tornou-se necessário que em todos os estabelecimentos públicos e privados, como pontos comerciais, estabelecimentos de serviços de saúde, lojas e de tráfegos, sejam disponibilizados o álcool a 70\%, que é utilizado como antisséptico e que se mostra bastante eficiente no combate de diversos parasitas, fungos, vírus e bactérias, já que esse produto foi projetado para eliminar 99,9\% desses germes. O que fez com que o consumo de álcoois a 70\% aumentasse significativamente em todo o mundo após a pandemia do novo coronavírus (covid-19).

(Brito et al.,2020.)

Dentre os diversos tipos de álcoois a 70\% que se pode encontrar nos comércios como: aerossol, líquido, gel que tem sido a opção mais adotada pelos usuários devido à adição dos agentes gelificantes que ajuda a diminui a irritabilidade e ressecamento da pele que álcool pode ocasionar. O Teor do álcool a 70\% garante a dissolução das camadas protetoras dos germes, matando-os em apenas alguns segundos. É importante lembrar que soluções alcoólicas em concentrações menores que $60 \%$ não fazem o efeito esperado no combate aos germes. Assim como soluções acima de $80 \%$, que evaporam muito mais rápido do que as camadas protetoras dos germes podem se desfazer (Burg. G, 2007; Santos et al, 2002).

O objetivo deste trabalho, portanto, é avaliar o teor alcoólico e as características físicas químicas de amostras de álcool que foram comercializadas em Vitória da Conquista, avaliando o seu pH e a viscosidade, analisar as características organolépticas correspondente em cada amostra. Além disso, os resultados obtidos serviram para que os estabelecimentos comerciais optem em produtos de fornecedores qualificados para os consumidores. 


\section{Metodologia}

O projeto seguirá o modelo de pesquisa experimental que se caracteriza por manipular diretamente variáveis relacionadas com o objeto de estudo e tem como finalidade testar hipóteses que dizem respeito à convicção de quem está pesquisando. O objetivo é, especialmente, compreender e explicar o problema que é objeto de estudo da pesquisa (Gil,2007).

Foram adquiridas 10 amostras, de marcas diferentes, de álcool líquido a 70\% com volume de 500mL cada disponíveis à venda no comércio local do município de Vitória da Conquista - Bahia. Uma quantidade de cada amostra, dentro do prazo de validade, foi armazenada em local de armazenamento seco, arejado e ao abrigo de luz para que não houvesse interferência nos testes físico-químicos que foram realizados na mesma semana. Outra parte de cada amostra esteve exposta à luz e às variações de temperatura em condições semelhantes àquelas das prateleiras dos estabelecimentos dos quais foram adquiridas.

A coleta foi realizada no período de agosto a setembro de 2021 seguindo os princípios do Guia de Controle de Qualidade de Produtos Cosméticos da ANVISA, na qual constam na resolução RDC 347/2020 e RDC 350/2020 (Brasil,2020e; 2020d). Todas as análises foram feitas de acordo com o Guia de Produção de Formulações Antissépticas Alcoólicas, onde constam as recomendações para o controle de qualidade e seus objetivos a serem adquiridos (ANVISA, 2020).

As amostras foram estudadas quimicamente, onde foram avaliadas as propriedades organolépticas, valor do $\mathrm{pH}$, viscosidade e teor alcoólico. Os ensaios foram feitos em triplicatas. As propriedades organolépticas foram avaliadas imediatamente após cada coleta.

\section{Avaliação organoléptica:}

Para a avaliação organoléptica, observou-se o estado físico de cada amostra, como a homogeneidade, a coloração e a transparência (opaco, transparente ou translucido), a viscosidade aparente (baixa, média, alta) bem como o odor de cada amostra (Brasil, 2004).

\section{Determinação de pH:}

Foi utilizado um pHmetro de bancada (Quimos Q400AS) previamente calibrado. Antes da verificação do valor de pH, as amostras precisavam estar diluídas na proporção de 1:10 em água purificada a 10\%, conforme orientação da ANVISA para produtos semissólidos (Brasil,2004). Após a preparação das amostras, o eletrodo transcorreu imerso diretamente na solução preparada, sendo consideradas três leituras sucessivas.

\section{Determinação da viscosidade:}

Foi determinada a viscosidade absoluta $(\mu)$ das amostras de álcool a 70\% líquido com base no viscosímetro de Stokes em que, por meio da velocidade da queda de uma esfera através do fluido, é possível calcular a viscosidade. A esfera de massa $5,71 \mathrm{~g}$ e raio de $9 \mathrm{~m}^{-3}$ foi colocada em uma proveta de $100 \mathrm{~mL}$ contendo a amostra do álcool, onde foi feita marcação na altura de $50 \mathrm{~cm}$ como a distância a ser percorrida pela esfera. A velocidade da esfera, medida a partir do tempo de descida, juntamente com a massa específica da solução à $25^{\circ} \mathrm{C}$ (Troy A. Scott, Jr, 1946) foram utilizadas para calcular a viscosidade absoluta ( $\mu$ ) expressa em Pa.s utilizando a relação de força peso, empuxo e resistência imposta pelo fluido à esfera.

\section{Verificação do teor alcoólico:}

Para avaliação do teor alcóolico do álcool líquido a 70\%, foi utilizado um refratômetro portátil de bancada, devidamente calibrado conforme manual, estando as amostras na temperatura de $25^{\circ} \mathrm{C}$. O teor alcoólico foi determinado pela comparação dos valores de índice de refração obtidos com valores encontrados na literatura para soluções etanol/água (Troy A. Scott, Jr, 1946). 


\section{Resultados e Discussão}

Após as aferições, verificou-se que todas as marcas comerciais de álcool que apresentavam a indicação de 92,8 INPM estão correspondentes ao $70^{\circ} \mathrm{GL}$ nos rótulos dos produtos que estavam corretamente graduados (Cechinel, 2003; Sequinel, 2020). Estes valores estão de acordo com os resultados obtidos nas pesquisas para o mesmo tipo de produto (ANVISA, 2020). Na Tabela 1 estão apresentados os resultados de acordo com as características organolépticas, pH, viscosidade, teor alcoólico e temperatura.

Tabela 1. Características organolépticas, $\mathrm{pH}$, viscosidade e teor alcoólico de amostras de álcool a $70 \%$ adquiridas nos estabelecimentos comerciais de Vitória da Conquista- Bahia.

\begin{tabular}{|c|c|c|c|c|c|c|}
\hline \multirow{2}{*}{ Amostra } & $\mathbf{p H}^{\mathbf{1}}$ & Viscosidade (s) & $\begin{array}{c}\text { Teor } \\
\text { alcoólico } \\
(\mathbf{\%})\end{array}$ & $\begin{array}{c}\text { Índice de } \\
\text { refração } \\
\text { medido }\end{array}$ & $\begin{array}{c}\text { Índice de } \\
\text { refração de } \\
\text { referência }{ }^{2}\end{array}$ & $\begin{array}{c}\text { Temperatura } \\
\left({ }^{\circ} \mathbf{C}\right)\end{array}$ \\
\hline $\mathbf{1}$ & $7,33 \pm 0,18$ & $01: 60$ & $89 \%$ & 1,36200 & 1,36200 & 24,2 \\
\hline $\mathbf{2}$ & $6,73 \pm 0,01$ & $03: 66$ & $89 \%$ & 1,36200 & 1,36200 & 24,4 \\
\hline $\mathbf{3}$ & $6,72 \pm 0,12$ & $01: 18$ & $68 \%$ & 1,36250 & 1,36251 & 24,2 \\
\hline $\mathbf{4}$ & $6,68 \pm 0,08$ & $01: 83$ & $68 \%$ & 1,36250 & 1,36251 & 23,4 \\
\hline $\mathbf{5}$ & $7,68 \pm 0,11$ & $00: 85$ & $68 \%$ & 1,36250 & 1,36251 & 24,5 \\
\hline $\mathbf{6}$ & $6,49 \pm 0,15$ & $01: 86$ & $68 \%$ & 1,36250 & 1,36251 & 24,3 \\
\hline $\mathbf{7}$ & $8,09 \pm 0,40$ & $00: 79$ & $68 \%$ & 1,36250 & 1,36251 & 24 \\
\hline $\mathbf{8}$ & $7,69 \pm 0,30$ & $02: 16$ & $68 \%$ & 1,36250 & 1,36251 & 24,1 \\
\hline $\mathbf{9}$ & $8,41 \pm 0,17$ & $00: 78$ & $89 \%$ & 1,36200 & 1,36200 & 23 \\
\hline $\mathbf{1 0}$ & $8,51 \pm 0,12$ & $00: 59$ & $89 \%$ & 1,36200 & 1,36200 & 24 \\
\hline
\end{tabular}

Fonte: Elaborada pelos autores (2021).

O aspecto (cor, odor e homogeneidade) das amostras analisadas se mostrou estável por 15 dias à luz solar, mostrandose de acordo com as recomendações do guia específico da ANVISA (Brasil,2004). No que se refere aos estabelecimentos comercias, na qual se o frasco de álcool estiver exposto diretamente à luz solar, há grande possibilidade de que o álcool e a água tenham sido evaporando, sobrando apenas o agente espessante. Vale-se ressalta que o álcool líquido a $70 \%$ possa diminuir a concentração do álcool em relação ao álcool em gel exposto a altas temperaturas, perdendo assim sua grande parte de sua eficácia.

Os resultados encontrados pelo teste de coeficiente do viscosímetro através do método de Stokes foram determinados pelo tempo de queda livre de uma esfera de metal. Os valores de tempo obtidos (Tabela 1) entre 00:59 a 03:66, são considerados razoáveis, referente ao menor volume do seu fluido, nessa relação serão mais facilmente adaptas aos ensaios de temperatura diferente da temperatura ambiente.

$\mathrm{O}$ pH caracteriza a acidez ou alcalinidade de uma determinada solução. A escala de pH varia entre 1 (ácido) e até 14(alcalino), sendo que o pH de valor 7 é considerado neutro (Brasil, 2004). Na Tabela 1 foram apresentados os resultados do pH das amostras estudadas em média e desvio padrão. Os valores de pH das amostras, situaram-se numa faixa de 6,49 a 8,51, mostrando-se de acordo com a literatura que diz que a tolerância biológica para produtos cutâneos possui pH na faixa 5,5 a 8,0 
(Auton, 2005). E boa atividade bactericida, de ação rápida na temperatura ambiente como pH ideal está em torno de 5,5 a 5,9 (Andrade, 2002), sendo capazes de reduzir toda a carga microbiana de determinados tecidos vivos. Outro ponto que podemos levar em conta que a temperatura, umidade e a pressão podem afetar as amostras, ou seja desestabilizando o pH das amostras, sendo de grande importância o armazenamento do produto, que deve estar em temperatura ambiente e a embalagens adequada (Santos et al., 2002). Em relação ao pH (Tabela 1) os resultados demonstraram que não ocorreram variações relevantes durante o tempo avaliado. Isso sugere que não houve formação de compostos de degradação ácidos ou básicos. Os ensaios foram conduzidos em condições de armazenamento à temperatura ambiente, nos dias previamente estabelecidos. (Vieira,2020).

Um método físico para dosagem de teor de álcool é o da refratometria, onde o índice de refração de uma solução varia regularmente com a concentração do soluto. Sendo assim, a composição da solução pode ser estimada através de seu índice de refração por comparação com tabelas de referência (Reis,2006) O refratômetro possui uma escala graduada em Brix segundo (Pilling, 2020), que é uma escala numérica que mede a quantidade de sólidos solúveis em uma solução de sacarose e, que se relaciona ao índice de refração através de uma tabela padrão de conversão. Sendo o índice de refração um dado universal, chegase a conversão para o fator buscado, sendo no caso o teor alcoólico. (Vieira, 2020). De acordo com as leituras feitas na Tabela 1 em comparação com os estudos de índice de refração do álcool etílico em misturas de água (Janina Nowakowsha ,1936) mostrou que o índice de refração de referência de 1,365 , estavam mais próximo de 1,3630 no que oscilou dentro dos limites da concentração do álcool a $70 \%$ líquido entre (18,9\% a 19\%), o que corresponde que estava mais próximo dentro dos padrões estabelecidos. Esses valores do índice eles diminuir conforme o aumento da temperatura que é determinado ao ponto máximo que é lentamente e poderá também cair conforme a faixa de temperatura e estabilizada na sua estrutura de refração que se tornara proporcionalmente com a expansibilidade máxima dos líquidos. Em temperaturas mais altas entre $25^{\circ}$ a $30^{\circ} \mathrm{C}$, os efeitos cinéticos podem ser relativos com a faixa limitantes das temperaturas.

Na Tabela 1 são apresentados os resultados do teor alcoólico das amostras estudadas. Os valores encontrados no alcoômetro volumétrico centesimal variaram de $79 \%$ a $80 \%$ p/p. Observa-se na tabela 1 que todas as amostras de álcoois possuam a concentração alcoólica recomendada pela ANVISA, entretanto as amostras tem sua viscosidade adequada segundo a $\operatorname{RDC~n}^{\circ}$ 46/2002. Foi possível verificar ainda, que as preparações alcoólicas para a higienização das mãos, na forma de álcool a $70 \%$ líquido, estava de acordo com a concentração final de 60\% a 80\% segundo as normas da (ANVISA, 2020). Devemos levar em conta, que a preparações possa conter emolientes nas formulações para evitar que haja ressecamento na pele, e é de fundamental importância seguir todas as instruções contidas no rótulo do produto quanto à forma de uso, aos riscos e aos cuidados no equipamento que será necessário para a sua aplicação.

A embalagem dos produtos deve ser permitida conforme os termos de acordo a resolução RDC 347/2020 e RDC 350/2020 (Brasil, 2020e; 2020d). Apresentando sua forma clara no rótulo, e sem aumento de toxicidade e não afetando a eficácia antibacteriana ou também na estabilidade do seu produto final, entretanto, deve proteger o produto por meio se ocorrer o extravasamento, contaminações químicas ou biológicas pelo contato com o ambiente ou até mesmo com as mãos. O álcool 70\% deve ser utilizado de acordo como seu prazo de validade e a indústria alcoolquímica ela permite a validade dos seus produtos um período de uns dois anos após a validação. Outro fato importante, que muitas dessas indústrias com matérias-primas para os hospitais, estabelecem o prazo de 6 meses da sua utilização, e, esses prazos de validades estão de acordo como produtos da embalagem lacrada (Santos et al., 2002).

Os resultados desses estudos quando comparados ao estudo realizado por (Pereira et al, 2015) sobre a análise físico química do álcool adquirido no município de Vitória da conquista, podem ser considerados semelhantes pois das 10 amostras do teor de álcool etílico mínimo de $70 \%$ p/p, estava conforme preconiza a Legislação RDC nº. 42/2010 para este tipo de produto (Brasil, 2010; Pereira et al, 2015). O índice de amostras apresentou teor alcoólico de 79\% a 80\% nesse trabalho foi ainda maior quando comparado ao estudo de (Tiyo et al., 2009), onde os resultados demostraram que as amostras de 1 a 10 estavam dentro 
dos valores estabelecidos para que o álcool exerça sua atividade desejado, tanto para antissepsia quanto para a desinfecção (Tiyo et al., 2009).

\section{Considerações Finais}

Os resultados encontrados nesse estudo possibilitam concluir que 79 a $80 \%$ das amostras analisadas possuem teor alcoólico adequado segundo normas da ANVISA, e dessa forma possivelmente possuem eficácia contra o vírus SARS-CoV-2, já que para isso o álcool deve estar a 70\%. É importante ressaltar que preparações alcoólicas devem ser manipuladas por técnicos habilitados, com a documentação legal necessária para realizar a fabricação. Contudo não houve nenhum erro durante a produção dos álcoois presentes, pois essas amostras possuía uma grande concentração de graduação alcoólica do que seria indicada no rotulo, o que também não ocorreu o interesse em fraude econômica, embora todas elas estavam sendo analisadas para o comércio local desses produtos. Sendo de importância transcendência, a iniciativa de promover a realização de orientações, reforçando informações sobre a aquisição do produto a partir de empresas idôneas e o adequado armazenamento para garantir a sua estabilidade e qualidade.

Em adição, a título de sugestão para trabalhos futuros, é necessária uma investigação cientifica e tecnológica, para o desenvolvimento de novas propostas estratégicas para a produção do álcool, a fim de promover qualidade e segurança no produto a ser desenvolvido e utilizado, evitando erros na sua produção e tendo um bom resultado na aquisição do produto final. Acentuando a importância do uso do álcool a 70\% na eliminação de microrganismos patógenos e na prevenção de infecções no ambiente hospitalar.

\section{Referências}

ANVISA. (2020). Orientações gerais produção de Formulações Antissépticas Alcoólicas.

Auton, M. E. (2005). Delineamento de Formas Farmacêuticas. (2a ed.), Artmed, 677.

Andrade, D. et al. (2002). Álcoois: A produção do conhecimento com ênfase na sua atividade antimicrobiana. revista da USP, v.35(1)

Burg, G. et al. (2007). Estudo da eficácia de um novo produto à base de álcool gel utilizado na antissepsia em um serviço de nefrologia. Medicina (Ribeirão Preto).

Brito. L. M et al. (2020). Produção de álcool em gel 70\% com diferentes precursores poliméricos. Rio de janeiro. Brasiliana Jornal of Jornal.

Brasil. (2020). Transmissão do SARS-CoV-2: implicações para as precauções de prevenção de infecção. Ministério da Saúde/Organização Pan-Americana da Saúde.

Brasil. (2010). Resolução da diretoria colegiada - RDC no 42, de 25 de outubro de 2010. Dispõe sobre a obrigatoriedade de disponibilização de preparação alcoólica para fricção antisséptica das mãos, pelos serviços de saúde do País, e dá outras providências. Brasília: Anvisa. Agência Nacional de Vigilância Sanitária.

Cechinel, R. B. (2003). A utilização do álcool no processo de higienização das mãos. EDITORA UFRGS.

Brasil. (2004). Séries Temáticas. Guia de estabilidade de produtos cosméticos, Agência Nacional de Vigilância Sanitária. Brasília, ANVISA.

Gil, A.C. (2007). Métodos e técnicas de pesquisa social. (4a ed.), Atlas.

Janina, N. (1939). The refractive índices of ethly alcohol and water mixtures. Master's theses.668.

Oliveira, W. K. \& Duarte, E; França, G. V. A. (2020). Como o Brasil pode deter a COVID-19. Epidêmico. Serv. Saúde.

Pereira, T. et al (2015). Avaliação da qualidade de diferentes marcas de álcool gel comercializadas na cidade de São Paulo. Boletim do instituto Adolfo Lutz. v, 25, n.1, p. 15 .

Pilling, S. (2020). Determinação do índice de refração de líquidos. EDITORA UNIVAP.

Quintella, C. M., Mata, A. M. T \& Ghesti, G. F. (2020). Vacinas para Coronavírus (COVID-19; SARSCOV-2): mapeamento preliminar de artigos, patentes, testes clínicos e mercado. Cadernos de prospecção. 13(1).

Reis, J. P. Z. (2006). Dosagem de etanol utilizando álcool desidrogenase de levedura de panificação. 66 f, dissertação (mestrado). EDITORA UNESP. 
Research, Society and Development, v. 10, n. 16, e474101624043, 2021

(CC BY 4.0) | ISSN 2525-3409 | DOI: http://dx.doi.org/10.33448/rsd-v10i16.24043

Sequinel, R. et al. (2020). Soluções a base de álcool para higienização das mãos e superfícies na prevenção da COVID-19:compêndio informativo sob o ponto de vista da química envolvida. São Paulo. Quím. Nova 43

Santos, A. A. M et al. (2002) Importância do Álcool no Controle de Infecções em Serviços de Saúde. Revista de Administração em Saúde. 4(16).

Troy A. S, Jr. (1946). Refractive index of etanol-water mixtures and density and density and refractive index of etanol-ethly ether mixtures, Peoria,Illions. Northem Regional Research Laboratory.

Tiyo, R. et al. (2009). Determinação do álcool 70\% utilizado para antissepsia em drogarias e farmácias de Maringá Paraná. Revista Brasileira em Farmácia. $90(3), 231-235$.

Vieira, G. S. (2015). Análise Sensorial: terminologia, desenvolvimento de padrões e treinamento de painelistas para a avaliação de produtos cosméticos. Dissertação (mestrado). Ribeirão Preto, São Paulo, Brasil. 